\title{
Genomic Markers Linked to Meloidogyne Chitwoodi Resistance Introgressed From Solanum Bulbocastanum to Cultivated Potato and Their Utilility in Marker-assisted Selection
}

\author{
Sapinder Bali \\ Washington State University \\ Charles Brown \\ USDA-ARS Temperate Tree Fruit and Vegetable Research Unit \\ Hassan Mojtahedi \\ USDA-ARS Temperate Tree Fruit and Vegetable Research Unit \\ Solomon Yilma \\ Oregon State University \\ Russell E Ingham \\ Oregon State University \\ Launa Cimrhakl \\ USDA-ARS Temperate Tree Fruit and Vegetable Research Unit \\ Rich Quick \\ USDA-ARS Temperate Tree Fruit and Vegetable Research Unit \\ Vidyasagar Sathuvalli ( $\square$ Vidyasagar@oregonstate.edu ) \\ Oregon State University https://orcid.org/0000-0001-5727-9987
}

\section{Research Article}

Keywords: SSR markers, high-throughput SNPs, INDEL markers, Nematode resistance, Columbia root-knot nematode, resistance breeding

Posted Date: August 4th, 2021

DOl: https://doi.org/10.21203/rs.3.rs-745462/v1

License: (9) (7) This work is licensed under a Creative Commons Attribution 4.0 International License. Read Full License 


\section{Abstract}

Meloidogyne chitwoodi is a major threat to potato production in the Pacific Northwest region of United States. Infected tubers are rendered unmarketable, hence growers' profitability is adversely affected. Breeding for nematode resistance is a long-term process and phenotyping the segregating populations for nematode resistance is the most time-consuming and laborious part of the process. Using DNA-based markers closely linked to the nematode resistance trait for marker-assisted selection (MAS) could enhance breeding efficiency and accuracy. In the present study, a pool of phenotyped progenies segregating for nematode resistance and susceptibility were fingerprinted using a $21 \mathrm{~K}$ single nucleotide polymorphism (SNP) array. Eight candidate SNPs located on potato Chromosome 11, segregating with the nematode resistance trait were identified and used as landmarks for discovery of other marker types such as, simple sequence repeat (SSR) and insertion-deletion (INDEL) markers. Subsequently, a total of eight SNPs, 30 SSRs and four INDELS located on scaffold 11 of Solanum. bulbocastanum were used to design primers; markers were validated on a panel of resistant and susceptible clones. Two SNPs (SB_MC1Chr11PotVar0066518 and SB_MC1Chr11-PotVar0064140), five SSRs (SB_MC1Chr11-SSR04, SB_MC1Chr11-SSR08, SB_MC1Chr11-SSR10, SB_MC1Chr11-SSR13 and SB_MC1Chr11-SSR20) and one INDEL (SB_MC1Chr11-INDEL4) markers differentated between the resistant and susceptible clones in the test panel as well as other segregating progenies using simple PCR technique and high resolution melting curve analysis. These markers are robust, highly reproducible and easy to use for MAS of nematode resistant potato clones to enhance the breeding program.

\section{Introduction}

The Pacific Northwest contributes approximately $65 \%$ of the total potato production in the United States, valued at \$2.21 Billion for 2019 (NASS-USDA 2020 ). Meloidogyne chitwoodi Golden et al. (Columbia root-knot nematode; CRKN) is a major pest of potato in this region (Santo et al. 1980). M. chitwoodi infects potato roots as well as tubers, causing both external and internal defects and reducing the market value of the crop. Preplant soil fumigation with nematicides and/or fumigants is the most effective approach to control CRKN populations. Soil fumigants and nematicides are not only expensive but also pose a threat to the environment and human health. Hence, growing potato varieties with natural resistance to most prevalent nematode populations would be an effective strategy, but at present none of the commercial potato varieties are resistant to CRKN.

Conventional breeding is the backbone of crop domestication and improvement. Although it is a time-consuming process, its benefits to modern agriculture supercede its drawbacks. In potato, natural resistance to CRKN was first identified in the diploid, wild species, Solanum bulbocastanum accession 22 (aka, SB22) (Austin et al. 1993). This race-specific resistance was mapped onto Chromosme 11 (Chr 11) using RFLP markers and the resistance is controlled by a single dominant locus $\mathrm{R}_{M C 1(b / b)}$ (Brown et al. 1996). This locus from $S$. bulbocastanum was introgressed into tetraploid potato using protoplast fusion and subsequent crossings with elite tetraploid cultivars (Brown et al. 1995; Mojtadehi et al. 1995). The result of this introgression was an advanced tetraploid breeding selection resistant to CRKN, PA99N82-4. Recent study using differential transcriptome analysis during nematode infection in PA99N82-4 suggests that the introgressed resistance is in the form of hypersensitive response and cell death, which is a characteristic response displayed by a single-dominant resistance gene (Bali et al. 2019).

PA99N82-4 is the main source of race-specific nematode resistance used in potato breeding program at Oregon State University. Phenotyping the breeding clones developed through controlled crosses is among the most time consuming and tedious parts of nematode resistance breeding. Phenotyping is typically performed in greenhouses or small trial plots. True potato seeds (resulting from controlled crosses) are germinated and tubers are harvested after $9-12$ weeks. Those seedling tubers are grown for up to 2-weeks in one gallon pots and young plants are inoculated with freshly extracted nematode eggs, which hatch out, infect the roots, and multiply for 8-12 weeks. Subsequently, infected plants are uprooted, roots are washed thoroughly, eggs are extracted and counted to calulate the multiplication/reproduction factor. These phenotype screening assays present the most challenging step in nematode resistance breeding thus resulting in selection and inclusion of a very limited number of plants for field trial assessment the following season. Molecular markers linked to resistance loci are promising alternative to phenotyping assays for nematode resistance screening; markers support the more efficient marker-assisted selection (MAS) and breeding processes.

The development of modern molecular biology techniques such as DNA markers have contributed immensely to the precision, accuracy and faster development of crop improvement tools and related processes (Dayteg and Tuvesson 2010). DNA fingerprinting is now integral to the plant breeding programs of major crops cultivated across the globe. It has contributed to the development of crop genetic resources while maintaining genetic diversity in germplasm resources (Nybom et al. 1991). There has been tremendous improvement to the genomic resources in potato breeding. Since the first potato genome published in 2011 by the international Potato Genome Sequencing Consortium (PGSC, 2011), potato breeders have had ready access to genomic information for its usage in enhancing their breeding programs. SpudDB (http://solanaceae.plantbiology.msu.edu/cgi-bin/gbrowse/potato/), a potato genomic resources database maintained by Michigan State University, houses genome browsers for the PGSC double monoploid S. tuberosum group Phureja DM v4.03 pseudomolecules, as well as the updated version of pseudomolecules (v6.1) (Hirch et al. 2014; Gina et al. 2020). These genome browsers also maintain data from potato RNA-Seq libraries from the SRA, and SolCAP SNP data (Hamilton et al. 2011; Felcher et al. 2012). SolCAP offers three types of high-throughput SNP fingerprinting readily available for potato through Neogen, Geneseek (Lincoln, NE). These are intervarietal potato SNPs (EST-derived SNPs from Bintje, Kennebec and Shepody), SolCAP 8300 Infinium chip (contains corresponding sequences, gene annotations and manifest and cluster file for further SNP analysis) and 69K SNP position and sequence context developed from RNAseq of Premier Russet, Atlantic and Snowden (this section also includes the details of Infinium 8300 SNP chip). SolCAP high-throughput SNP fingerprinting has made it possible to access details and locations of markers at the genomic level and use the sequence information to design primers for further analysis of other potato varieties, clones or populations.

In the present study, we used a combined phenotyping-genotyping methodology on a pool of segregating nematode resistant and susceptible clones using high-throughput SNP markers to locate the markers linked with resistance locus $\mathrm{R}_{M C 1(b / b)}$ on $S$. bulbocastanum Chr11. We first phenotyped several advanced selections for nematode resistance in the greenhouse and selected five each of resistant and susceptible clones for high throughput SNP-genotyping using 21K SNPs. The primary source of nematode resistance, SB22 and the immediate introgressed resistant parent PA99N82-4 were also genotyped with the same 
SNP array. All the markers clearly segregating with the trait and located on Chr11 were further analyzed. These validated DNA-markers can be effectively used for MAS in potato to select the nematode resistant lines for their inclusion in the early development of the program. This will dramatically reduce the time required to phenotype the individual clones to identify the promising nematode resistant clones, thus enhancing potato breeding outcomes.

\section{Materials And Methods}

\section{Plant material}

The clones used for genotyping and bulk segregation were developed and phenotyped at USDA-ARS, Prosser, WA. The population used for marker validation was developed and phenotyped at Oregon State University. Tubers were planted in the green house and fresh leaf material was collected for DNA isolation.

Nematode resistance phenotyping: All clones used in the study were first phenotyped for nematode resistance in the greenhouse. True potato seeds from the crosses with PA99N82-4 as pistillate parent were germinated on root-initiation media; multiple cuttings were transferred to individual tissue culture tubes containing propagation media. Four-week-old tissue culture seedlings were transferred to a pasteurized mix of sand and virgin sandy loam soil in one gallon clay pots. Each plant grew for two-weeks, and was then inoculated with 5000 M. chitwoodi eggs. The pots received regular watering for 8 weeks ( 55 days) under greenhouse conditions. Subsequently, plants were uprooted, roots were washed thoroughly under tap water and eggs were extracted by the $\mathrm{NaOCl}$ (hypochlorite) method (Hussey 1973). Extracted eggs were counted using $1 \mathrm{ml}$ counting slide to calculate a reproduction factor $(\mathrm{R})$ : $\mathrm{R}=\mathrm{final}$ egg density $\div$ initial egg density (Mojtahedi et al. 1988) to determine whether the clone was resistant or susceptible to M. chitwoodi. Clones with lower egg densities were considered resistant.Five resistant and five susceptible clones were used for high-throughput SNP fingerprinting along with SB22 (diploid resistance source) and PA99N82-4 (tetraploid resistant parent) (Table 1).

Table 1

Segregating clones phenotyped for nematode resistance and susceptibility. These clones were the genotyping pool and panel for validation of developed markers in the present study.

\begin{tabular}{|c|c|c|c|c|c|c|c|}
\hline Clone ID & Female $x$ Male & Phenotype & Egg col & tt (5 repl & ates)- Ju & he 2016 & \\
\hline PA07NCK16-52 & 82-4xRusset Bulk & $S$ & 87500 & & & & \\
\hline PA07NCK16-55 & 82-4xRusset Bulk & $\mathrm{R}$ & 840 & 702 & 1440 & & \\
\hline PA07NCK16-64 & 82-4xRusset Bulk & $S$ & 14976 & & & & \\
\hline PA07NCK17-53 & 82-4xWestern & $S$ & 13200 & & & & \\
\hline PA07NCK17-54 & 82-4xWestern & S & 8208 & & & & \\
\hline PA07NCK17-61 & 82-4xWestern & $\mathrm{R}$ & 0 & 0 & 270 & 0 & 0 \\
\hline PA07NCK17-64 & 82-4xWestern & $\mathrm{R}$ & 300 & 252 & 216 & & \\
\hline PA07NCK11-51 & 82-4xAlturas & $\mathrm{R}$ & 0 & 0 & 0 & 0 & \\
\hline PA07NCK11-55 & 82-4xAlturas & $\mathrm{R}$ & 300 & 270 & 0 & & \\
\hline PA07NCK11-56 & 82-4xAlturas & $\mathrm{R}$ & 240 & 0 & 240 & 0 & \\
\hline PA07NCK11-60 & 82-4xAlturas & S & 12690 & & & & \\
\hline PA07NCK11-63 & 82-4xAlturas & $S$ & 14400 & & & & \\
\hline PA07NCK12-54 & 82-4xMWTX2609-4RU & $S$ & 46080 & & & & \\
\hline PA07NCK12-55 & 82-4xMWTX2609-4RU & $S$ & 15840 & & & & \\
\hline PA07NCK12-61 & 82-4xMWTX2609-4RU & $\mathrm{R}$ & 480 & 0 & 0 & & \\
\hline PA07NCK12-65 & 82-4xMWTX2609-4RU & $\mathrm{R}$ & 228 & 0,0 & 1200 & 660 & \\
\hline PA07NCK10-53 & 82-4xA95109-1 & $S$ & 5520 & 27600 & 21600 & 15120 & \\
\hline PA07NCK10-54 & $82-4 \times A 95109-1$ & $\mathrm{R}$ & 330 & 150 & 0 & 210 & \\
\hline PA07NCK10-66 & $82-4 \times A 95109-1$ & $S$ & 19500 & & & & \\
\hline PA07NCK10-69 & 82-4xA95109-1 & $\mathrm{R}$ & 0 & 630 & 174 & & \\
\hline PA07NCK8-51 & 82-4xGemstar & $S$ & 11520 & & & & \\
\hline PA07NCK8-53 & 82-4xGemstar & $S$ & 40320 & & & & \\
\hline PA07NCK8-54 & 82-4xGemstar & $\mathrm{R}$ & 0,0 & 0,0 & 240 & 2500 & \\
\hline PA07NCK8-62 & 82-4xGemstar & $\mathrm{R}$ & 350 & 272 & 300 & & \\
\hline
\end{tabular}

\section{DNA isolation}


DNA isolation was performed using a slightly modified Dellaporta protocol described by Presting et al. 1995. Briefly, $500 \mathrm{mg}$ of fresh leaf tissue was placed in an Agdia grinding bag (Agdia Inc., Elkhart, IN) with $1.5 \mathrm{ml}$ of freshly prepared extraction buffer (100 mM Tris, 50 mM EDTA, $500 \mathrm{mM} \mathrm{NaCl}$ and $10 \mathrm{mM} 2-$ mercaptoethanol). Tissue was ground completely using a marble pestle; the slurry was collected over a mesh filter to avoid tissue debris, and placed into a 2 $\mathrm{ml}$ centrifuge tube to which $100 \mu \mathrm{l}$ of $10 \%$ SDS was added. After thorough mixing, the tube contents were incubated at $65^{\circ} \mathrm{C}$ for $30 \mathrm{minutes}$. Subsequently, 200 $\mu \mathrm{l}$ of $5 \mathrm{M}$ potassium acetate was added to the slurry and incubated on ice for 15 minutes, followed by centrifugation at 12,000 rpm for $5-6$ minutes to separate the tissue debris. The clear supernatant was transferred to a fresh tube. DNA was precipitated by adding $300 \mu$ l of cold isopropanol and holding the tube on ice for up to 30 minutes. The DNA pellet was washed with $70 \%$ ethanol, dried completely and dissolved in $100 \mu \mathrm{DNase}$-free ultrapure water. DNA quality and quantity were evaluated with Nanodrop (Thermo Fisher Scientific, Waltham, MA) and stored at $-20^{\circ} \mathrm{C}$ until use.

\section{SNP fingerprinting}

Approximately $400 \mathrm{ng}$ of high quality DNA of five nematode resistant and five susceptible clones, resistant parent PA99N82-4 and source of nematode resistance (S. bulbocastanum accession 22 or SB22) were sent to GeneSeek (Lincoln, NE) for SNP fingerprinting using $21 \mathrm{~K}$ SNP array. SNP data analysis was performed as described in Bali et al. 2017. Briefly, raw SNP data was analyzed by the Genome Studio-Tetraploid version and allelic data was exported as an Excel file. All the SNPs checked for quality manually in order to eliminate the monomorphic SNPs and SNPs with $\geq 10 \%$ no call rate (Table 2).

Table 2

Summary of the SNP markers used to fingerprint nematode resistant and susceptible pool in the present study.

\begin{tabular}{|lllllllll|}
\hline DNA_ID & No_Calls & Calls & Call_Rate & AAAA_Freq & AAAB_Freq & AABB_Freq & ABBB_Freq & BBBB_Freq \\
\hline Resistant 1 & 303 & 20923 & 0.9857 & 0.2147 & 0.1473 & 0.1453 & 0.176 & 0.3166 \\
\hline Resistant 2 & 197 & 21029 & 0.9907 & 0.2141 & 0.147 & 0.1487 & 0.1737 & 0.3166 \\
\hline Resistant 3 & 107 & 21119 & 0.995 & 0.2393 & 0.1317 & 0.1329 & 0.1543 & 0.3418 \\
\hline Resistant 4 & 115 & 21111 & 0.9946 & 0.2277 & 0.1427 & 0.1343 & 0.1683 & 0.327 \\
\hline Resistant 5 & 145 & 21081 & 0.9932 & 0.2429 & 0.1211 & 0.1396 & 0.152 & 0.3445 \\
\hline Susceptible 1 & 116 & 21110 & 0.9945 & 0.2271 & 0.1407 & 0.141 & 0.1668 & 0.3243 \\
\hline Susceptible 2 & 129 & 21097 & 0.9939 & 0.2173 & 0.1513 & 0.1339 & 0.1797 & 0.3178 \\
\hline Susceptible 3 & 159 & 21067 & 0.9925 & 0.2429 & 0.1256 & 0.137 & 0.152 & 0.3424 \\
\hline Susceptible 4 & 151 & 21075 & 0.9929 & 0.2371 & 0.1366 & 0.1308 & 0.1581 & 0.3376 \\
\hline Susceptible 5 & 146 & 21080 & 0.9931 & 0.2337 & 0.1365 & 0.1315 & 0.1599 & 0.3383 \\
\hline S. bulbocastanum(SB22) & 2622 & 18604 & 0.8765 & 0.4021 & 0.0098 & 0.0106 & 0.011 & 0.5664 \\
\hline
\end{tabular}

Identification of SNP, SSR and INDEL markers linked to nematode resistance: Shortlisted SNP markers were checked using SNP-pool genotype segregation across the five resistant and five susceptible breeding clones, PA99N82-4 and SB22 for segregation with the nematode resistance trait. We identified 15 potential SNP markers, of which eight, four and three were located on Chr11, Chr10 and Chr01, respectively. Based on the SNP locations in the S. tuberosum genome in SpudDB Genome Browser, 150 bp upstream and downstream sequences were downloaded and aligned with the $S$. bulbocastanum reference genome (http://solanum.cgrb.oregonstate.edu/cgi-bin/gb2/gbrowse/solanum/) using local NCBI blastn 2.2.29 to fetch all the complementary sequences and locate the region spanned by those SNPs. S. bulbocastanum scaffold 11 was scanned for SSRs and INDELS. The $~ 6$ Mbs of scaffold 11 was run in the SSR locator (Da Maia et al. 2008) to find all the SSRs.

Primer designing: The complementary sequences of all SNP markers selected from $S$. tuberosum were extracted from the $S$. bulbocastanum reference genome using blastn (Linux version) to design primers. SSR and INDEL marker sequences from S. bulbocastanum were also used for primer design. All primers were designed using Oligo Analyzer (Integrated DNA Technology, Coralville, IA) with the following parameters: primer length between 18-28 bp, >40\% GC content, melting temperature $55-60^{\circ} \mathrm{C}$ and negligible hairpins and self-dimers. A total of 49 primer pairs were designed.

Marker validation: All designed primers were tested on a set of phenotyped nematode resistant and susceptible potato clones (twelve resistant and seven susceptible). Amplifications were performed using MyTaq ${ }^{\mathrm{TM}}$ DNA Polymerase (Bioline, Meridian Bioscience, Memphis, TN). Reaction mix containing a final concentration of $1 \mathrm{X}$ PCR buffer, $0.5 \mu \mathrm{M}$ primer mix, 0.5 units of Taq Polymerase, $5 \%$ DMSO and 30ng template DNA was run at following cycling conditions: $95^{\circ} \mathrm{C}$ for 1.30 minutes, followed by 40 cycles of $95^{\circ} \mathrm{C}$ for 20 seconds, $\mathrm{Tm}^{\circ} \mathrm{C}$ (refer to Table 4 for primer specific annealing temperature) for 15 seconds and $72^{\circ} \mathrm{C}$ for 15 seconds, with a final extension at $72^{\circ} \mathrm{C}$ for 5 minutes. The PCR product was fractionated using $1.2 \%$ agarose gels run at $95 \mathrm{~V}$ for 5 hours, stained with an ethidium bromide solution, and visualized with a BIO-RAD Universal Hood II Gel Doc system (Bio-Rad laboratories, Hercules, CA). All 49 markers were first tested using PCR followed by agarose gel electrophoresis (PCR-AGE). 
Table 4

Eight potential markers located on Scaffold 11 of Solanum bulbocastanum (SB22) linked to Meliodogyne chitwoodi resistance in potato. S. bulbocastanum was sequenced by Sathuvalli et al. unpublished data.

\begin{tabular}{|c|c|c|c|c|c|c|c|}
\hline Marker ID & Type & Scaffold\#SB22 & Location & Forward Primer [5'-3'] & Reverse Primer [5'-3'] & $\mathrm{Tm}$ & $\begin{array}{l}\text { Expected } \\
\text { product } \\
\text { size }\end{array}$ \\
\hline $\begin{array}{l}\text { SB_MC1Chr11- } \\
\text { PotVar0066518 }\end{array}$ & $\mathrm{C} / \mathrm{G}$ & Scaffold11 & $39,042,195$ & $\begin{array}{l}\text { GTA CTA TGA CAT GTA } \\
\text { TGG GAA GGC GG }\end{array}$ & $\begin{array}{l}\text { AAG GAA TTA GAG TAC ATT } \\
\text { TTT TCC TAG CAT GC }\end{array}$ & $58^{\circ} \mathrm{C}$ & $118 \mathrm{bp}$ \\
\hline $\begin{array}{l}\text { SB_MC1Chr11- } \\
\text { PotVar0064140 }\end{array}$ & $\mathrm{G} / \mathrm{C}$ & Scaffold11 & $41,641,229$ & $\begin{array}{l}\text { CTG TTG CTA ACA CAG } \\
\text { ATA GGC TGC TAG C }\end{array}$ & $\begin{array}{l}\text { GAA GCA TAC AGT AAG GTA } \\
\text { ACA CTT CGA TGG G }\end{array}$ & $58^{\circ} \mathrm{C}$ & $124 \mathrm{bp}$ \\
\hline $\begin{array}{l}\text { SB_MC1Chr11- } \\
\text { SSR04 }\end{array}$ & $(\mathrm{GAA}) 7$ & Scaffold11 & $37,120,922$ & $\begin{array}{l}\text { CCA AAC CGA CAC TAA } \\
\text { CCG AAC CGA C }\end{array}$ & $\begin{array}{l}\text { CTA GGA GAG AAG TTG GCC } \\
\text { ACG G }\end{array}$ & $58^{\circ} \mathrm{C}$ & $240 \mathrm{bp}$ \\
\hline $\begin{array}{l}\text { SB_MC1Chr11- } \\
\text { SSR08 }\end{array}$ & (TGT)11 & Scaffold11 & $37,468,954$ & $\begin{array}{l}\text { CCA AGT TAC CCT CCC } \\
\text { CAG ACA C }\end{array}$ & $\begin{array}{l}\text { CAC TTA ATG TAA AGT CAC } \\
\text { TTC TGC GAC G }\end{array}$ & $58^{\circ} \mathrm{C}$ & $270 \mathrm{bp}$ \\
\hline $\begin{array}{l}\text { SB_MC1Chr11- } \\
\text { SSR10 }\end{array}$ & $(\mathrm{TGC}) 7$ & Scaffold11 & $38,165,332$ & $\begin{array}{l}\text { CAG ACG ACG CCG GTG } \\
\text { GTG }\end{array}$ & $\begin{array}{l}\text { CAT TAT CAT ACG CCG CCT } \\
\text { CCG TGT C }\end{array}$ & $60^{\circ} \mathrm{C}$ & $400 \mathrm{bp}$ \\
\hline $\begin{array}{l}\text { SB_MC1Chr11- } \\
\text { SSR13 }\end{array}$ & $(\mathrm{GA}) 14$ & Scaffold11 & $39,002,528$ & $\begin{array}{l}\text { GAA ACC TCA CTG ACC } \\
\text { ATG TTT CTC C }\end{array}$ & $\begin{array}{l}\text { CGT ATG ATG GTT GCT GAT } \\
\text { GTT CAC C }\end{array}$ & $58^{\circ} \mathrm{C}$ & $330 \mathrm{bp}$ \\
\hline $\begin{array}{l}\text { SB_MC1Chr11- } \\
\text { SSR20 }\end{array}$ & (GATAG) 5 & Scaffold11 & $40,098,001$ & $\begin{array}{l}\text { GCA TGG AAC ACA CGT } \\
\text { ACA ACG C }\end{array}$ & $\begin{array}{l}\text { GGG CTC TTA TCC CCT CCA } \\
\text { ACT G }\end{array}$ & $58^{\circ} \mathrm{C}$ & $285 \mathrm{bp}$ \\
\hline $\begin{array}{l}\text { SB_MC1Chr11- } \\
\text { INDEL4 }\end{array}$ & $\begin{array}{l}24 \mathrm{bp} \\
\text { deletion }\end{array}$ & Scaffold11 & $39,898,836$ & $\begin{array}{l}\text { CCT GCG TAG GGC AGT } \\
\text { CAG CTT ATC }\end{array}$ & $\begin{array}{l}\text { CTG CTT TAG CCT ACT GTG } \\
\text { AAA CTG ACT TG }\end{array}$ & $58^{\circ} \mathrm{C}$ & $175 \mathrm{bp}$ \\
\hline
\end{tabular}

Supplementary Fig. 1: High Resolution Melting curve analysis of progeny OR09007with SNP marker SB_MC1Chr11-PotVar0066518. The red, green and yellow variants include Meloidogyne chitwoodi resistant progenies; the blue variant includes susceptible progenies.

High resolution melting curve analysis: Markers showing readable polymorphism in PCR-AGE were also tested using HRM curve analysis. Approximately 30 ng of template were amplified using HRM master mix (Applied Biosystems, Foster City, CA) and $0.5 \mu \mathrm{M}$ primer mix. The mix was amplified using Quant Studio 3 (Applied Biosystems, Foster City, CA) following the 'Standard Curve with Melt Fast' protocol. The protocol consisted of three stages: Stage $1-95^{\circ} \mathrm{C}$ for 10 minutes; Stage 2: 40 cycles at $95^{\circ} \mathrm{C}$ for 15 seconds and $60^{\circ} \mathrm{C}$ for 1 minute; followed by melt curve or Stage $3-95^{\circ} \mathrm{C}$ for 10 seconds, $60^{\circ} \mathrm{C}$ for 1 minute, $95^{\circ} \mathrm{C}$ for 15 seconds, $60^{\circ} \mathrm{C}$ for 15 seconds, with a final hold at $16^{\circ} \mathrm{C}$. The melting curve data was recorded and analysed using High Resolution Melt software v3. 1 desktop version (Applied Biosystems, Foster City, CA).

\section{Marker assisted selection in breeding}

To further validate potential markers, we used a segregating progeny (OR09007) of 96 individual clones resulting from the cross PA99N82-4 X C098067-7RU developed by Oregon state University. A subset of 24 of these clones had been phenotyped in the green house for nematode resistance as described above. The progenies were screened using all promising SNP, SSR and INDEL markers.

\section{Results And Discussion}

Since nematode resistant potato varieties with acceptable agronomic traits are still unavailable and considering the environmental hazards associated with the use of harmful soil fumigants, there is an urgent need to expedite the breeding process. Conventional breeding for nematode resistance is a lengthy process and phenotyping of offspring for nematode resistance is the most time consuming and tedious part. Conventional breeding further limits the number of progenies tested and selected for further agronomic trials. In the past, DNA-based markers linked to nematode resistance loci have been successfully used in MAS and breeding. For example, PCR-based DNA markers linked to Mi resistance locus in tomato were developed and used by Williamson et al. 1994; Cregan et al. 1999 identified SSR markers linked to soybean cyst nematode resistance conditioned by rhg1. More recently, Smith et al. 2018 developed and successfully used SNP markers linked to locus MJR1, a resistance locus for Meloidogyne javanica, for MAS and breeding in grapevine. Although STS markers were earlier reported for screening M. chitwoodi resistance in potato by Zhang et al. in 2007, these markers were not only difficult to reproduce across populations but also resulted in false fingerprints during our intial screening for nematode resistance. It may be that these markers are not tightly linked with the $\mathrm{R}_{M C 1(b / b)}$ locus and are lost during the recombination events in advanced selections. We are seeking more advanced and robust co-dominant SNP, SSR and INDEL markers in potato, for their potential contribution to our breeding program. In the present study, we utilized high-throughput SNP genotyping of segregating phenotyped clones generated by crossing nematode resistant and susceptible parents to develop robust markers for MAS. An advanced selection, PA99N82-4, was used as the pestilate parent and is source of resistant in all crosses. Susceptible parents included popular Russet varieties such as GemStar, Alturas, Western Russet and Russet bulk (Table 1). These selections had been phenotyped for nematode resistance multiple times; those with > 5000 egg counts (more than initial inoculumn) were considered susceptible. The selections with lower egg counts were phenotyped at least four more times to confirm resistance. Five susceptible selections with high $(>10,000)$ egg counts and five resistant selections with close to zero egg counts in majority of the replicates were selected and SolCAP Infinium SNP array with 21K SNP markers were used to genotyping (Supplementary File 1). Affordable high-throughput SNP fingerprinting services allow us to take advantage of these resources.. All the fingerprinted samples showed high call rate ( $\geq 0.98)$ except SB22 (0.87 call rate; Table 2). The low SNP call rate in SB22 could be due to the fact that SNP markers were developed from the cultivated potato; $S$. bulbocastanum. being a diploid wild relative of cultivated potato is expected to posses genomic variations resulting in low SNP call rate. Of an average $20 \mathrm{~K}$ SNPs called, 15 SNPs showed clear segregation with the nematode resistance phenotype (Table 3, Supplementary File 1). Looking further into the locations of the potential SNPs on the potato genome, four were located on Chr10, eight on Chr11 and three on Chr 01 (Table 3). We were interested in SNPs on Chr11 because the locus of 
$\mathrm{R}_{M C 1(b / b)}$ is mapped on Chr11 (Brown et al. 1996). A total of eight SNPs located on Chr11 were shortlisted for further analysis. We then looked for the corresponding SNPs in S. bulbocastanum genome. This genome was sequenced by Oregon State University (Sathuvalli et. al. unpublished) and is publicly available at http://solanum.cgrb.oregonstate.edu/cgi-bin/gb2/gbrowse/solanum/. All SNPs could be located on the $S$. bulbocastanum scaffold 11 which corresponds to $S$. tuberosum $\mathrm{Chr11}$ (Table 3). A 6Mb region was marked with the borderline corresponding SNPs; the sequence was manually processed to identify other potential marker types including SSRs and INDELS. There are 1259 SSRs and 18 INDELS in the region. We selected 15 SNP's, 30 SSR's and four INDELS for marker development and validation using a panel of 12 phenotyped nematode resistant and seven susceptible potato clones, including 10 clones that were initially genotyped for marker discovery. Most of the markers developed are highly reproducible and easy to scan using PCR-AGE and a highly advanced and faster technology such as HRM curve analysis. HRM is a relatively new technique that uses melting or dissociation of the PCR product to detect variations in DNA sequences. The differences are recorded by quantification of the dsDNA binding dyes during the dissociation step. HRM circumvents the requirement for gel electrophoresis in order to check the marker segregation patterns. We were especially interested in developing HRM assays for potential markers because this technique is much faster and less tedious and could be mutilplexed to scan larger number of progenies (1-96-samples in one reaction) in just $1.5 \mathrm{~h}$ for nematode resistance or susceptibilty. One marker, SB_MC1Chr11-PotVar0066518, can be used as a dual marker. It amplifies a 120 bp product in the resistant clones and does not amplify in the susceptible clones (it requires a longer electrophoresis run). SB_MC1Chr11-PotVar0066518 clearly distinguishes the clones in melting curve analysis as two variants (resistant and susceptible; Fig. 1). In addition to SNP markers, SSRs are the markers of choice for MAS and breeding due to their high polymorphic information content, co-dominant nature and abundance in plant genomes (Gupta and Varshney 2000). Five SSR markers, SB_MC1Chr11-SSR04, SB_MC1Chr11-SSR08, SB_MC1Chr11-SSR10, SB_MC1Chr11-SSR13 and SB_MC1Chr11-SSR20 differentiated the panel using simple PCR-AGE. Three of the SSR markers, SB_MC1Chr11-SSR04, SB_MC1Chr11-SSR08, SB_MC1Chr11-SSR10 contain trinucleotide repeat motifs of $(\mathrm{GAA})_{7},(\mathrm{TGT})_{11}$, and $(\mathrm{TGC})_{7}$, respectively. One of the markers, SB_MC1Chr11-SSR13, is a dinucleotide repeat (GA) 14 whereas SB_MC1Chr11-SSR20 is a pentanucleotide repeat $(G A T A G)_{5}$. The only INDEL marker (SB_MC1Chr11-INDEL4) that could successfully differentiate the selected panel contained a 24 bp deletion. Based on their power to differentiate and ease of scoring, we recommend using a set of at least three markers SB_MC1Chr11-SSR10, SB_MC1Chr11-INDEL4 and SB_MC1Chr11-PotVar0066518 to generate reliable passport data for the progeny selection (Fig. 2). SB_MC1Chr11-SSR10 and SB_MC1Chr11-INDEL4 can be used as PCR-AGE and SB_MC1Chr11-PotVar0066518 can be used as PCR-AGE as well as HRM curve analysis (refer to Table 4 for summary of eight markers). In order to test the utility of these markers for MAS, we screened segregating progeny (OR09007) of 96 individual clones developed by crossing PA99N82-4 X C0098067-7RU. A subset of these clones (24) were phenotyped to validate the accuracy of marker segregation, which was $100 \%$ accurate with SB_MC1Chr11-SSR10, SB_MC1Chr11-INDEL4 and SB_MC1Chr11-PotVar0066518 thus validating the potential of these markers to be used for MAS (Fig. 2, Supplementary Fig. 1).

Table 3

Fifteen selected SNP markers developed from Phureja and the genotype called across the resistant and susceptible pool, PA99N82-4 and SB22. The markers provided an anchor point to shortlist SSR and INDEL markers.

\begin{tabular}{|c|c|c|c|c|c|c|c|c|c|c|c|c|c|}
\hline \multirow[t]{2}{*}{ Lab ID } & \multirow[t]{2}{*}{ SNP ID } & \multirow[t]{2}{*}{ Chr. position } & \multirow[t]{2}{*}{ Location } & \multicolumn{5}{|c|}{ Nematode resistant genotypes } & \multicolumn{5}{|c|}{ Nematode susceptible genotypes } \\
\hline & & & & R1 & R2 & R3 & R4 & R5 & S1 & S2 & S3 & S4 & S5 \\
\hline SNP1 & PotVar0064192 & ST4.03CH11 & 403271 & ABBB & ABBB & ABBB & ABBB & ABBB & BBBB & BBBB & BBBB & BBBB & BBBB \\
\hline SNP2 & PotVar0064502 & ST4.03CH11 & 787571 & ABBB & ABBB & ABBB & ABBB & ABBB & BBBB & BBBB & BBBB & BBBB & BBBB \\
\hline SNP3 & PotVar0064663 & ST4.03CH11 & 811351 & ABBB & ABBB & ABBB & ABBB & ABBB & BBBB & BBBB & BBBB & BBBB & BBBB \\
\hline SNP4 & PotVar0066518 & ST4.03CH11 & 2706412 & ABBB & ABBB & ABBB & ABBB & ABBB & BBBB & BBBB & BBBB & BBBB & BBBB \\
\hline SNP5 & solcap_snp_c2_21017 & ST4.03CH11 & 5314456 & ABBB & ABBB & ABBB & AABB & ABBB & BBBB & BBBB & BBBB & BBBB & BBBB \\
\hline SNP6 & PotVar0064012 & ST4.03CH11 & 397921 & AAAB & AAAB & AAAB & AAAB & AAAB & AAAA & AAAA & AAAA & AAAA & AAAA \\
\hline SNP7 & PotVar0064140 & ST4.03CH11 & 399077 & AAAB & AAAB & AAAB & AAAB & AAAB & AAAA & AAAA & AAAA & AAAA & AAAA \\
\hline SNP8 & PotVar0064152 & ST4.03CH11 & 399202 & AAAB & AAAB & $A A A B$ & AAAB & AAAB & AAAA & AAAA & AAAA & AAAA & AAAA \\
\hline SNP9 & PotVar0065428 & ST4.03CH10 & 1101113 & ABBB & ABBB & ABBB & ABBB & AABB & BBBB & BBBB & BBBB & BBBB & BBBB \\
\hline SNP10 & PotVar0065297 & ST4.03CH10 & 1131216 & ABBB & ABBB & ABBB & ABBB & ABBB & BBBB & BBBB & BBBB & BBBB & BBBB \\
\hline SNP11 & PotVar0120180 & ST4.03CH10 & 3196115 & ABBB & ABBB & AABB & ABBB & ABBB & BBBB & BBBB & BBBB & BBBB & BBBB \\
\hline SNP12 & PotVar0122649 & ST4.03CH10 & 59673985 & AAAB & AAAB & $A A A B$ & AAAB & AAAB & AAAA & AAAA & AAAA & AAAA & AAAA \\
\hline SNP13 & solcap_snp_c1_16516 & ST4.03CHO1 & 11769461 & ABBB & ABBB & ABBB & ABBB & ABBB & BBBB & BBBB & BBBB & BBBB & BBBB \\
\hline SNP14 & solcap_snp_c2_14489 & ST4.03CH01 & 65782007 & ABBB & ABBB & ABBB & ABBB & ABBB & BBBB & BBBB & BBBB & BBBB & BBBB \\
\hline SNP15 & solcap_snp_c2_14762 & ST4.03CH01 & 86750499 & ABBB & ABBB & ABBB & ABBB & AABB & BBBB & BBBB & BBBB & BBBB & BBBB \\
\hline
\end{tabular}

MAS is a useful tool to replace greenhouse phenotyping for nematode resistance screening to enhance breeding efforts. Markers developed in the present study show promise for our breeding program for MAS and development of nematode resistant potato varieties for Pacific Northwest, a major potato producing region in the United States.

\section{Conclusion}


Using modified resistant-susceptible genotype segregrant analysis, SNP genotyping and genome sequence mining we developed eight breeder-friendly markers linked to resistance locus for $M$. chitwoodi resistance in potato. Of these eight markers, a set of three markers are robust and have the potential for use in marker-assisted breeding.

\section{Declarations}

Ethics approval and consent to participate (Human Ethics, Animal Ethics or Plant Ethics): Not Applicable

Consent for publication: All authors (except CB and HM, who are now deceased) have approved the manuscript for publication.

Availability of data and material: All data generated or analyzed in this study are included in the published article and supplementary files.

Conflicts of interest/Competing interests: Authors declare no conflict of interest.

Funding: Funding for this work is provided by Northwest Potato Research Consortium and the USDA-ARS state partnership award.

Authors' contributions: SB and VS designed the research; SB performed all the experiments including genotyping, data analysis, marker validation, progeny screening and manuscript preparation; VS conceptualized the project, secured the funding, supervised and reviewed the manuscript; SY, LC, RQ, CB, HM, RI helped in breeding and phenotyping of the progenies.

Acknowledgements: Authors would like to thank Aguilar Moises for technical help.

\section{References}

1. Austin S, Pohlman JD, Brown CR, Mojtahedi H, Santo GS, Douches DS, Helgeson JP(1993) Interspecific somatic hybridization between Solanum tuberosum L. and S. bulbocastanum Dun. as a means of transferring nematode resistance. American Potato Journal 70(6):485 - 95

2. Bali S, Sathuvalli V, Brown C, Novy R, Ewing L, Debons J, Douches D, Coombs J, Navarre D, Whitworth J, Charlton B (2017) Genetic fingerprinting of potato varieties from the northwest potato variety development program. Am J Potato Res 1(1):54-63 94(

3. Bali S, Vining K, Gleason C, Majtahedi H, Brown CR, Sathuvalli V (2019) Transcriptome profiling of resistance response to Meloidogyne chitwoodi introgressed from wild species Solanum bulbocastanum into cultivated potato. BMC Genomics 20(1):1-8

4. Brown CR, Yang CP, Mojtahedi HA, Santo GS, Masuelli RI (1996) RFLP analysis of resistance to Columbia root-knot nematode derived from Solanum bulbocastanum in a BC 2 population. Theor Appl Genet 92(5):572-576

5. Brown CR, Mojtahedi H, Santo GS (1995) Introgression of resistance to Columbia and northern root-knot nematodes from Solanum bulbocastanum into cultivated potato. Euphytica 83(1):71-78

6. Cregan PB, Mudge J, Fickus EW, Danesh D, Denny R, Young ND (1999) Two simple sequence repeat markers to select for soybean cyst nematode resistance coditioned by the rhg1 locus. Theor Appl Genet 99(5):811-818

7. Dayteg C, Tuvesson S (2010) Automation of DNA Marker Analysis for Molecular Breeding in Crops. In: Molecular Techniques in Crop Improvement. Springer, Dordrecht, pp 143-161

8. Da Maia LC, Palmieri DA, De Souza VQ, Kopp MM, de Carvalho Fl, Costa de Oliveira A (2008) SSR locator: tool for simple sequence repeat discovery integrated with primer design and PCR simulation. International journal of plant genomics

9. Diambra LA (2011) Genome sequence and analysis of the tuber crop potato Nature 475

10. Felcher KJ, Coombs JJ, Massa AN, Hansey CN, Hamilton JP, Veilleux RE, Buell CR, Douches DS (2021) Integration of two diploid potato linkage maps with the potato genome sequence. PloS one 27(4):e36347 7(

11. Pham GM, Hamilton JP, Wood JC, Burke JT, Zhao H, Vaillancourt B, Ou S, Jiang J, Buell CR (2020) Construction of a chromosome-scale long-read reference genome assembly for potato. Gigascience 9(9): giaa100

12. Gupta PK, Varshney RK (2000) The development and use of microsatellite markers for genetic analysis and plant breeding with emphasis on bread wheat. Euphytica 113(3):163-185

13. Hamilton JP, Hansey CN, Whitty BR, Stoffel K, Massa AN, Van Deynze A, De Jong WS, Douches DS, Buell CR (2011) Single nucleotide polymorphism discovery in elite North American potato germplasm. BMC genomics12(1):1-2

14. Hirsch CD, Hamilton JP, Childs KL, Cepela J, Crisovan E, Vaillancourt B, Hirsch CN, Habermann M, Neal B, Buell CR (2014) Spud DB: A resource for mining sequences, genotypes, and phenotypes to accelerate potato breeding. The Plant Genome 7(1):plantgenome2013-12

15. Hussey RS (1973) A comparison of methods of collecting inocula of Meloidogyne spp., including a new technique. Plant Dis Rep 57:1025-1028

16. Mojtahedi H, Brown CR, Santo GS (1995) Characterization of Resistance in a Somatic Hybrid of Solanum bulbocastanum and S. tuberosum, to Meloidogyne chitwoodi. Journal of Nematology 27(1):86

17. Mojtahedi H, Santo GS, Wilson JH (1998) Host tests to differentiate Meloidogyne chitwoodi races 1 and 2 and M. hapla. Journal of Nematology 20(3):468

18. NASS-USDA (2020) https://www.nass.usda.gov/Statistics_by_State/Washington/Publications/Potatoes/2020/PT09_1.pdf

19. Nybom H (1991) Applications of DNA fingerprinting in plant breeding. In DNA fingerprinting: approaches and applications (pp. 294-311) Birkhäuser Basel

20. Presting GG, Smith OP, Brown CR (1995) Resistance to potato leafroll virus in potato plants transformed with the coat protein gene or with vector control constructs. Phytopathology 85(4):436-442 
21. Santo GS, O'bannon JH, Finley AM, Golden AM (1980) Occurrence and host range of a new root-knot nematode (Meloidogyne chitwoodi) in the Pacific Northwest. Plant Dis 64(10):951-952

22. Smith HM, Smith BP, Morales NB, Moskwa S, Clingeleffer PR, Thomas MR (2018) SNP markers tightly linked to root knot nematode resistance in grapevine (Vitis cinerea) identified by a genotyping-by-sequencing approach followed by Sequenom MassARRAY validation. PLoS One 20(2):e0193121 13(

23. Williamson VM, Ho JY, Wu FF, Miller N, Kaloshian I (1994) A PCR-based marker tightly linked to the nematode resistance gene, Mi, in tomato. Theor Appl Genet 87(7):757-763

24. Zhang LH, Mojtahedi H, Kuang H, Baker B, Brown CR (2007) Marker-Assisted Selection of Columbia Root-Knot Nematode Resistance Introgressed from Solanum bulbocastanum. Crop Sci 47(5):2021-2026

\section{Figures}

R R R S R R R S R R R S S R R R R S R R
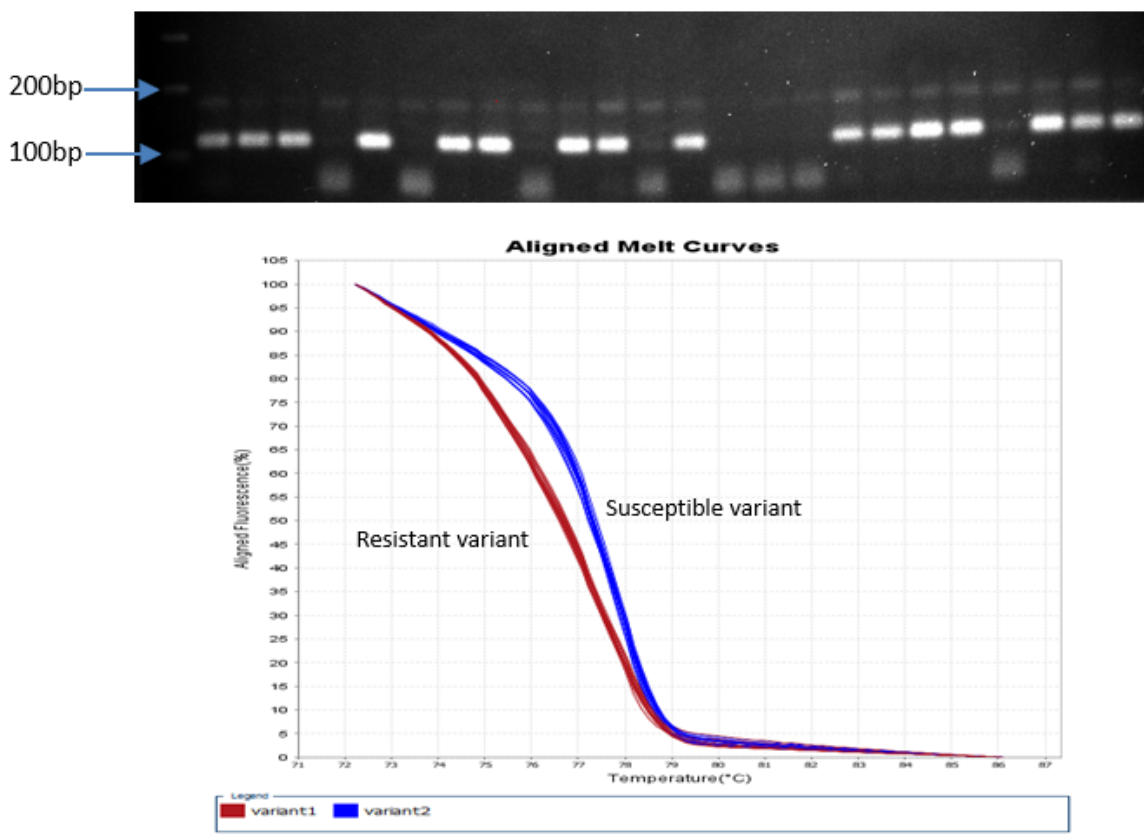

Figure 1

The potential of SB_MC1Chr11-PotVar0066518 as a dual marker. This marker can be used for PCR-AGE (longer run) and HRM (High Resolution Melt) curve analysis.

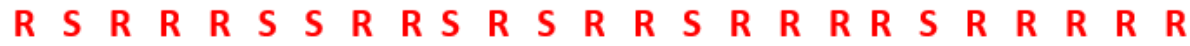

(A)

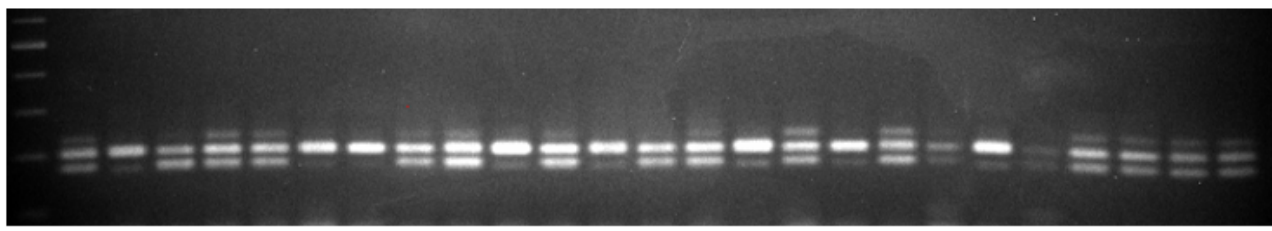

(B)

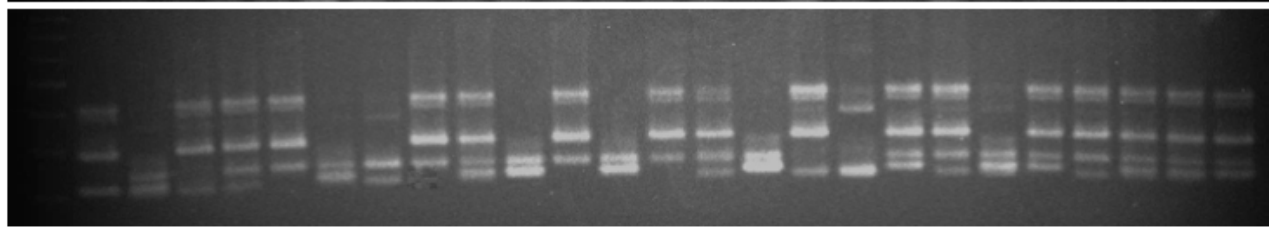

(C)

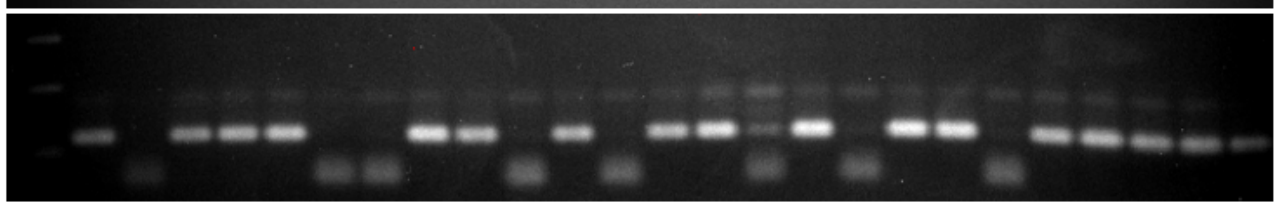

\section{Figure 2}

Representative gel slide showing 25 progenies (OR09007) PA99N82-4 X C0098067-7RU) scanned using three different markers (A) SB_MC1Chr11-INDEL4 (B) SB_MC1Chr11-SSR10 (C) SB_MC1Chr11-PotVar0066516. All three markers successfully differentiated nematode resistant and susceptible clones. 


\section{Supplementary Files}

This is a list of supplementary files associated with this preprint. Click to download.

- floatimage3.png 